\title{
Price Control Effectiveness in the Context of a Supply Chain
}

\author{
T. Tavor ${ }^{1}$, U. Spiegel ${ }^{2,3} \&$ M. Weber ${ }^{4}$ \\ ${ }^{1}$ Department of Economics and Management, Max Stern Academic College of EmekYezreel, Yezreel Valley, \\ Israel \\ ${ }^{2}$ Department of Management, Bar-Ilan University, Ramat Gan, Israel \\ ${ }^{3}$ Department of Economics, University of Pennsylvania, Philadelphia, USA \\ ${ }^{4}$ Ono Academic College, Faculty of Business Administration and Bar-Ilan University Department of \\ Management, Ramat Gan, Israel \\ Correspondence: T. Tavor, Department of Economics and Management, Max Stern Academic College of \\ EmekYezreel, Yezreel Valley, Israel. E-mail: tchai2000@yahoo.com
}

Received: November 9, 2016

Accepted: November 17, $2016 \quad$ Online Published: February 7, 2017

doi:10.5539/res.v9n1p189

URL: http://dx.doi.org/10.5539/res.v9n1p189

\begin{abstract}
The imposition of price controls on a well-functioning competitive market is usually considered harmful to society since it reduces the volume of trade and creates incentives to waste resources. Generally, regulation and control of non-competitive markets in a supply chain environment are very difficult tasks, since the source that maintains and accelerates monopoly induced price increases is unclear.

This present paper deals with the case of an entire supply chain with several stations when the economic environment is under a monopoly or duopoly regime and price control in such an environment can be a very useful and corrective policy that may lead to a higher degree of efficiency along with desired redistributional influences.
\end{abstract}

Keywords: price control, regulation, supply chain, monopoly producer and retailers, marketers

\section{Introduction and Literature Review}

A policy of price control in a competitive environment is detrimental to society by reducing trade, and leading to inefficient resource allocations, fewer discoveries and less innovation. This process often occurs primarily over the long term. For example, Morton (2001) claims, “...the imposition of price controls on a well-functioning, competitive market harms society by reducing the amount of trade in the economy and creating incentives to waste resources. Many researchers have found that price controls reduce entry and investment in the long run and can also reduce quality, create black markets and stimulate costly rationing.... More generally, the reference price chosen by the government rises because of a change in the underlying forces of demand or supply". Many researchers have found that price controls reduce entry and investment in the long run. In the case of the high-tech industry and other sophisticated markets such as pharmaceuticals, the most detrimental is likely to be the reduction in innovation, which harms future generations. Although policymakers know that price controls can be very harmful, they continue to have strong incentives to legislate low prices for themselves. This is a kind of more sophisticated price control. The government targets its price according to some reference price in the economy rather than choosing a fixed number, or sets its price a fixed amount below that of other customers.

The overwhelming evidence against price controls naturally leads to a consideration of other methods of lowering purchasing costs. Instead of price controls the private sector uses a number of methods that are both effective and consistent with a market economy. Such approaches used by the private market are much less damaging to economic welfare than government imposed price controls.

Some of these methods may be summarized and analyzed in comparison to the popular policy of a price ceiling, which is easily enforced but not very efficient for implementing a more favorable welfare distribution.

Although very popular worldwide, the heavy subsidization of the dairy product industry does not exist in Israel. Nevertheless, the number of milk producers in 2015 was about 801 and the volume of production reached 1,372 million liters. 
In contrast, there is almost an absolute prohibition on import of most dairy products, especially those that are basic and necessary goods. However, some products are exported to Europe or the United States as well as to several neighboring countries.

Similar to Canada, Israel uses a supply management program for milk production by means of milk quotas. The program limits production with strict rationing and penalties imposed on the surpluses of competing milk producers.

In the Israeli pricing policy for milk, the authorities determine a target price. It is a minimum price paid to the dairy farmers that is based on the weighted average cost of food for the cows, wages for the workers, investment in the infrastructure and machinery at the cowshed or in the industry, the market interest rates, energy cost, and a minimum profits guarantee to the dairy farmers. This target price is paid for a given quota that is determined by the Israeli Dairy Board.

Again, it is emphasized that there is no price support and purchase of surpluses, or import restrictions and export subsidies such as those that exist in the United States and in several Western European countries.

All of the tools mentioned above can be enhanced, thereby allowing the farmers to maintain profitability and a reasonable standard of living, rather than setting a price ceiling or a price floor.

However, the research of Mayrice Dogon (2011) indicates that some support measures provide private farmers a little incentive to be more efficient in terms of costs reduction and to pursue economies of scale as compared with a non-supply management system. As in all measures of intervention by authorities, one may gain or lose from applying the supply management system.

This system was commonly and widely used in Israel during the twentieth century. However, in the last few decades it has been completely discontinued.

Still, the intervention of antimonopoly authorities is recommended. Rudakova et al. (2015) claim that the legitimacy of such intervention depends not only on the market share values of economic entities but also on another factor. They state, "This requires, at least, the presence of anti-competitive behaviour in the market, reducing the prices to a level or below the prime cost, entering into agreements aimed against partners and others".

This paper also investigates the effect of regulations imposed on non-competitive markets such as a monopoly or duopoly. Regulations on monopoly power can be applied using several methods. However the ability to accomplish and improve either the quality of the product or social welfare by imposing these regulatory devices becomes more complicated when the supply chain is comprised of several links or in an environment with many junctions along the supply chain. Lee and Billington (1993) provide this definition of a supply chain:

"A supply chain is a network of facilities that performs the functions of procurement of material, transformation of material to intermediate and finished products, and distribution of finished products to customers."

In their paper, they identify the need for a decentralized supply chain model that allows for the following:

1) A generalized network structure,

2) Uncertainties in supply, demand, and internal processes (as opposed to demand only),

3) Simplicity and tractability for computation, and

4) Capacitated production systems.

The current paper offers a more simplified approach.

The simple case of a market structure where many consumers face a price determined by the manufacturer (supplier) who is regulated by a price ceiling is very well known in the literature. There are efficient and corrective measures for achieving a Pareto improvement. In reality the picture is far more complicated. As more links exist along the supply chain, the question arises as to when to impose the regulation. When there are more agents along the chain, their desire to coordinate and generate more monopoly power and thus more profits is likely to prevail. Cachon and Lariviere (2005) present an example of such a situation in which a revenue-sharing contract between retailer(s) and a supplier along with other cooperative behavior may increase their mutual and private profits. The above referenced paper and others referred to below follow Spengler (1950), who claims that horizontal integration may lead to a less satisfactory allocation of resources and generates monopoly power and price increases. In contrast, vertical integration may intensify competition and lead to price decreases, rather than suppress competition. As described below, more recent papers have dealt with vertical integration and introduce our case of vertical integration in the Israeli cheese market. 
The issue of price regulation has recently been raised in several papers. Krishnan and Winter (2007) show an approach of pricing decisions along a supply chain. It models an upstream manufacturer selling to two outlets, which compete as a differentiated duopoly with uncertain demand and spillover between the outlets. Krishnan and Winter (2010) adopt a methodology in which an individual retailer's incentives for marginal changes in price and inventory are compared with the collective payoff of the supply chain in order to identify incentive distortions. Bandyopadhyay and Paul (2010) look for the equilibrium strategy in a competitive setting involving two competing manufacturers vying to be the "preferred supplier" for a retailer. The retailer, in turn, is trying to maximize its expected profit from the trades that ensue.

These markets are characterized by the possibility that the supply side is comprised of several or possibly many links in the supply chain.

Douglas Ball (2011) considers the pharmacy industry regulation. He raises the questions of whether the regulation of mark-ups eventually leads to lower drug prices for consumers, and whether the regulation should be imposed along the supply chain at the producer stage, at the wholesale stage, or at the retail stage.

Ball searched for evidence concerning Low and Middle Income Countries (LMICs) with various kinds of policy regulation. His main conclusions regarding the regulation of mark-ups in the medicine industry are that regulation strategy needs to be imposed comprehensively on manufactures, retailers, and other intermediate agents along the supply chain. Mark-up regulation is, as expected, more complicated to apply in the private sector than in the public sector. Appropriate and significant enforcement is required for regulation to be effective. Eventually Ball concludes that "there was no evidence as to whether regulation of such commercial practices would be effective in reducing medicine prices".

Ball also examines different methods of price control along the supply chain of medical items, using appropriate and effective regulation. Among those avenues he mentions fixed percentage mark-ups that are most common in LMICs. They are accomplished by setting a price that is a fixed percentage above cost, or alternatively proportionally reducing profit margins. He also raises the possibility of a price cap that is adopted in this paper.

Ball emphasizes that these regulatory devices may be efficient for a competitive environment, but may reduce quality and reliability of the product or of the service offered to the consumer.

In this sense Ball raises similar arguments to those of Biglaiser and Riordan (2000) who deal with the dynamics of price regulation adjustment to exogenous technological progress. They show that a naive implementation of price regulation may lead to deficient levels of capacity in the case of depreciation costs of historical investments that could result in less efficient capital replacement decisions.

This kind of supply chain can be extended further. For example, in a closed loop supply chain, a chain with links of suppliers of a new good is combined with a parallel reverse channel for the collection of used products from customers for remanufacturing (See Canan Savaskan, 2004). A further extension of supply chain arrangements could include supply chain coordination through rational contracts such as buyback contracts among customers, retailers and producers (Pasternack, 1985; Song et al., 2008; Shen \& Willems, 2012; Lokendra Devangan et al., 2013). These kinds of arrangements increase the monopoly power of the producer, but also make it more complicated for the public authorities to impose control and regulation.

This complicated question of how, where, and in which control channels regulation should be imposed brings back in some sense the traditional papers of the 1970's which dealt with applying quality standards on monopoly power or rate of return regulations in order to move society closer to a social optimum (See e.g., Spence, 1975).

The present paper adopts the old device of a price ceiling as a tool to improve and redistribute social welfare between suppliers and customers. It presents a real case study of the cheese market in which the supply channel is composed of three different suppliers: monopoly, duopoly and competitive firms that are vertically related.

The study examines the case of an entire supply chain with several stations when the economic environment is under a monopoly or a duopoly regime. Price control in such an environment can be a very useful and corrective policy that may lead to a higher degree of efficiency along with desired redistributional influences.

Intervention by the policymaker or regulator is very welcome in a simple market structure where one monopoly producer faces many competing consumers and thereby gains a significant portion of the total wealth (while the consumers are left with a small portion of that wealth in the form of a reduced consumer surplus). A price ceiling below the price set by the monopoly and closer to the perfectly competitive level in most cases leads to an increase of the society's total wealth and a larger portion of that total wealth being shared by consumers (This would exclude the case of a natural monopoly in which a competitive market cannot survive). 
The description above typifies a simple market structure which is not too realistic in the present day since the supply side is not limited only to producer(s) but extends to a whole supply chain of both producers and retailers (marketers). This paper introduces a simple case in which several intermediate agents are involved in the production and marketing process, and it shows how the total society wealth as well as the wealth distribution is affected by applying a standard regulation to the basic structure of the vertical integrated economics.

In a case study the paper investigates the pricing policy for a final good, hard cheese as well as cottage cheese, that moves through different stages of the supply side before finally being sold to the private consumer. Actually, this case played an important role in Israel during the summer of 2011 when the exorbitant profit margins of a monopoly dairy along with a few large retailers led to a consumer protest and massive street demonstrations, which became known as the cottage cheese rebellion.

Another and even more realistic example occurred several years earlier in Israel. A very popular dairy product named "Milky" was exclusively introduced in the market by a single manufacturer. Since this chocolate dessert was very popular both among children and adults, it therefore demonstrated a very inelastic demand. The product was produced using milk at an isolated factory at Yotveta, a kibbutz in the desert near the city of Eilat. It was distributed primarily to two large distributors that sold it in network stores to domestic competing customers. The milk required for production was supplied by many small dairy farmers. Due to the factory location in the desert, these farmers were forced to sell the milk as competitors subject to the monopoly of the "Milky" producer. The profit margin of the monopoly was very large as a result of price discrimination that became known to Israeli customers when the same product was sold to Germany or the United States at a price lower than the domestic price, despite the higher delivery cost to these countries. This revelation brought about a customer protest against the pricing policy of the "Milky" monopoly, which subsequently forced the authorities to set a price ceiling.

Four stages of a supply chain can be demonstrated with a more well-known example in the United States concerning cream cheese.

The following are the simplified stages of the cheese industry:

Stage A. Several competing farmers (for example, farmers in Pennsylvania ) grow the grass, feed and milk the cows, etc., and sell their milk as raw material to a monopoly (the cream cheese factory) that is the only milk buyer and the only cheese producer. The monopoly uses the milk as the only variable factor in the production of cheese.

Stage B. The monopoly cheese producer sells the cheese to two large competing chain retailers which are big brand name supermarkets.

Stage $C$. The two retailers then resell the cheese to many competing consumers. They are permitted to add to the basic price charged by the monopoly cheese producer a certain given and equal profit margin level which is assumed to be given and is not controlled by the two retailers.

Stage D. In the final stage, D, the total consumers' outlay is distributed among the three kinds of supplying agents: a) The competing farmers who are the milk producers; b) The cheese manufacturer monopoly; and c) The two retailers who are intermediate agents between the preceding suppliers and the competing customers.

The total wealth of the cheese industry production is distributed in a certain manner in the absence of any kind of regulatory control or any other kind of policymaker intervention. However, intervention in the form of setting a price ceiling on the price that retailers are allowed to charge the consumers may change not only the total wealth created by the cheese industry, but also the wealth distribution amongst the various sectors. The present paper investigates these results, how robust they are, and whether or not regulatory intervention is desired and welcomed by the different economic agents along the supply chain. The next section of the study develops a very simple model, without regulation, of the four sectors involved in the process from milk production until the final stage in which customers buy and pay for the cheese. In an additional section, the study allows the regulator to set a price ceiling on cheese. The changes in the size and the distribution of wealth and the differences of the values between the two scenarios before and after regulation are then investigated. The final section concludes the paper.

\section{The Model of the Free Market}

We assume that the factor (milk), $S$, is produced by many competing farmers $j=1 \ldots n$

$$
S=\sum_{j=1}^{n} S_{j}
$$


Due to the law of diminishing marginal productivity, the marginal cost is increasing, and thus the prices charged by the farmers of $S$ increase at a constant rate, $\delta$, that represents the price sensitivity charges due to an additional unit of milk as a factor for cheese production:

$$
P^{S}(S)=\delta \cdot S
$$

From (1.2) we can derive the total profit of the farmers as:

$$
\Pi^{S}=\frac{\delta \cdot S^{2}}{2}
$$

The cheese production, $Q$, maintains constant returns to scale as follows:

$$
Q=\gamma^{-1} \cdot S=\frac{1}{\gamma} \cdot S \text { or } S=\gamma \cdot Q
$$

Such that the marginal productivity of milk as a factor introduction of cheese is constant and equals $\gamma$. The total production of cheese is sold by the monopoly producer to two retailers, $i$, where $i=1,2$.

The monopoly faces two different linear demand curves that represent the demand of each retailer as a function of the price charged by the monopoly.

The demand of each retailer $i$ that the monopoly faces is:

$$
P_{i, t}^{M}=A_{i}-q_{i, t}
$$

Where $A_{i}(i=1,2)$ represents the reservation price of each retailer $i$ and $q_{i, t}$ represents the quantity that the monopoly producer sells to each of the two retailers.

Thus, the monopoly profit is:

$$
\Pi_{t}^{M}=\sum_{i=1}^{2}\left(A_{i}-q_{i, t}\right) \cdot q_{i, t}-P^{S}(S)_{t} \cdot \sum_{j=1}^{n} S_{j, t}
$$

Where the cost to the monopoly of the milk input is:

$$
P^{S}(s)_{t} \cdot \sum_{j=1}^{n} S_{j, t}=\delta \cdot\left(\sum_{j=1}^{n} S_{j, t}\right)^{2}
$$

From equation (1.1) and (1.4) we get:

$$
\sum_{i=1}^{2} q_{i, t}=\gamma^{-1} \cdot\left(\sum_{j=1}^{n} S_{j, t}\right)
$$

From (1.7) and (1.8) we derive:

$$
P^{S}(S)_{t} \cdot \sum_{j=1}^{n} S_{j, t}=\gamma^{2} \delta\left(\sum_{i=1}^{2} q_{i, t}\right)^{2}
$$

Based on (1.9) the monopoly profit function of (1.6) can be rewritten as:

$$
\Pi_{t}^{M}=\sum_{i=1}^{2}\left(A_{i}-q_{i, t}\right) \cdot q_{i, t}-\gamma^{2} \delta\left(\sum_{i=1}^{2} q_{i, t}\right)^{2}
$$

By solving the F.O.C. of the monopoly with respect to both variables $q_{1, t}$ and $q_{2, t}$ we get: 


$$
\frac{d \Pi_{t}^{M}}{d q_{1, t}}=A_{1}-2 q_{1, t}-2 \gamma^{2} \delta\left(\sum_{i=1}^{2} q_{i, t}\right)=0
$$

and

$$
\frac{d \Pi_{t}^{M}}{d q_{2, t}}=A_{2}-2 q_{2, t}-2 \gamma^{2} \delta\left(\sum_{i=1}^{2} q_{i, t}\right)=0
$$

From (1.11) and (1.12) we can define the optimal relationship between quantities and prices by defining the cross effects between the quantities of the two retailers as:

$$
q_{1, t}=\frac{A_{1}-2 \gamma^{2} \delta \cdot q_{2, t}}{2+2 \gamma^{2} \delta}
$$

and

$$
q_{2, t}=\frac{A_{2}-2 \gamma^{2} \delta \cdot q_{1, t}}{2+2 \gamma^{2} \delta}
$$

From (1.5) and (1.13) and (1.14) we find the cross effects between the price charged by a retailer and the quantities sold by the rival retailer:

$$
P_{1, t}^{M}=\frac{\left(1+2 \gamma^{2} \delta\right) A_{1}+2 \gamma^{2} \delta \cdot q_{2, t}}{2+2 \gamma^{2} \delta}
$$

as well as:

$$
P_{2, t}^{M}=\frac{\left(1+2 \gamma^{2} \delta\right) A_{2}+2 \gamma^{2} \delta \cdot q_{1, t}}{2+2 \gamma^{2} \delta}
$$

From (1.13) and (1.14) we can define $q_{1, t}$ as a function of all the parameters as follows:

$$
q_{1, t}=\frac{\left(2+2 \gamma^{2} \delta\right) A_{1}-2 \gamma^{2} \delta \cdot A_{2}}{2\left(2+4 \gamma^{2} \delta\right)}
$$

and symmetrically:

$$
q_{2, t}=\frac{\left(2+2 \gamma^{2} \delta\right) A_{2}-2 \gamma^{2} \delta \cdot A_{1}}{2\left(2+4 \gamma^{2} \delta\right)}
$$

The last two terms of (1.17) and (1.18) can be inserted at (1.10) which represents the total profit function of the monopoly from total sales to retailers as follows:

$$
\begin{aligned}
\Pi_{t}^{M} & =\left[A_{1}-\frac{\left(2+2 \gamma^{2} \delta\right) A_{1}-2 \gamma^{2} \delta \cdot A_{2}}{2\left(2+4 \gamma^{2} \delta\right)}\right] \cdot \frac{\left(2+2 \gamma^{2} \delta\right) A_{1}-2 \gamma^{2} \delta \cdot A_{2}}{2\left(2+4 \gamma^{2} \delta\right)}+ \\
& +\left[A_{2}-\frac{\left(2+2 \gamma^{2} \delta\right) A_{2}-2 \gamma^{2} \delta \cdot A_{1}}{2\left(2+4 \gamma^{2} \delta\right)}\right] \cdot \frac{\left(2+2 \gamma^{2} \delta\right) A_{2}-2 \gamma^{2} \delta \cdot A_{1}}{2\left(2+4 \gamma^{2} \delta\right)}- \\
& -\gamma^{2} \delta \cdot\left[\frac{\left(2+2 \gamma^{2} \delta\right) A_{1}-2 \gamma^{2} \delta \cdot A_{2}}{2\left(2+4 \gamma^{2} \delta\right)}+\frac{\left(2+2 \gamma^{2} \delta\right) A_{2}-2 \gamma^{2} \delta \cdot A_{1}}{2\left(2+4 \gamma^{2} \delta\right)}\right]^{2}
\end{aligned}
$$


or

$$
\begin{aligned}
\Pi_{t}^{M} & =\frac{\left(2+6 \gamma^{2} \delta\right) A_{1}+2 \gamma^{2} \delta \cdot A_{2}}{2\left(2+4 \gamma^{2} \delta\right)} \cdot \frac{\left(2+2 \gamma^{2} \delta\right) A_{1}-2 \gamma^{2} \delta \cdot A_{2}}{2\left(2+4 \gamma^{2} \delta\right)}+ \\
& +\frac{\left(2+6 \gamma^{2} \delta\right) A_{2}+2 \gamma^{2} \delta \cdot A_{1}}{2\left(2+4 \gamma^{2} \delta\right)} \cdot \frac{\left(2+2 \gamma^{2} \delta\right) A_{2}-2 \gamma^{2} \delta \cdot A_{1}}{2\left(2+4 \gamma^{2} \delta\right)}- \\
& -\gamma^{2} \delta \cdot\left[\frac{\left(2+2 \gamma^{2} \delta\right) A_{1}-2 \gamma^{2} \delta \cdot A_{2}}{2\left(2+4 \gamma^{2} \delta\right)}+\frac{\left(2+2 \gamma^{2} \delta\right) A_{2}-2 \gamma^{2} \delta \cdot A_{1}}{2\left(2+4 \gamma^{2} \delta\right)}\right]^{2}
\end{aligned}
$$

or

$$
\Pi_{t}^{M}=\frac{\left(1+3 \gamma^{2} \delta+2 \gamma^{4} \delta^{2}\right)\left(A_{1}^{2}+A_{2}^{2}\right)-2 \gamma^{2} \delta\left(1+2 \gamma^{2} \delta\right) \cdot A_{1} A_{2}}{\left(2+4 \gamma^{2} \delta\right)^{2}}
$$

Since the total revenue of the milk producer is the production cost of the monopoly based on (1.2) and (1.3) above, the profit of the milk producer is:

$$
\Pi^{S}=\frac{\gamma^{2} \delta}{2} \cdot\left[\frac{\left(2+2 \gamma^{2} \delta\right) A_{1}-2 \gamma^{2} \delta \cdot A_{2}}{2\left(2+4 \gamma^{2} \delta\right)}+\frac{\left(2+2 \gamma^{2} \delta\right) A_{2}-2 \gamma^{2} \delta \cdot A_{1}}{2\left(2+4 \gamma^{2} \delta\right)}\right]^{2}
$$

or

$$
\Pi^{S}=\frac{\gamma^{2} \delta\left(A_{1}+A_{2}\right)^{2}}{2\left(2+4 \gamma^{2} \delta\right)^{2}}
$$

At this stage we introduce the profit function of both retailers, while assuming that each retailer determines a certain ratio of profit margin. If retailer $i$ is charged by the monopoly a price of $P_{i, t}^{M}$, then the retailer determines the price he charges consumers as $P_{i, t}^{R}=(1+\alpha) P_{i, t}^{M}$ or

$$
P_{i, t}^{R}=(1+\alpha)\left(A_{i}-q_{i, t}\right)
$$

Where $\alpha$ represent the percentage of price increase that the retailers charge from the customers above the price charged by the producer.

In order to determine the actual quantities and prices at equilibrium we have to derive the relationship between the quantities sold to each retailer. For this purpose we first define the market share of cheese sales for each of the two retailers, $M S_{i}$, as follows:

$$
M S_{1, t}=\frac{q_{1, t}}{\sum_{i=1}^{2} q_{i, t}}=\frac{q_{1, t}}{q_{1, t}+q_{2, t}}
$$

Therefore,

$$
q_{2, t}=\left(\frac{1-M S_{1, t}}{M S_{1, t}}\right) \cdot q_{1, t}=\left(\frac{M S_{2, t}}{M S_{1, t}}\right) \cdot q_{1, t}=M S_{21, t} \cdot q_{1, t}
$$

Where $M S_{21, t}$ is defined as the ratio between the market shares of the two retailers at period $t$. 
The regular and simple approach is that the value of $M S_{j i, t}$ is a simple division of purchasing power of both companies, measured by the actual sales that each retailer determines independently of his previous sales history. However, the present paper uses a different and more sophisticated or modified approach that each retailer holds and recognizes an historical memory and reacts accordingly. It assumes that each retailer's share at a given period can be expressed as a weighted average between retailers 1 and 2 based on information of the accumulated shares of the previous two periods. These values are defined as $A M S_{i j, t-1, t-2}$ for $i \neq j$

$$
A M S_{21, t-1, t-2}=\varepsilon \cdot M S_{21, t-1}+(1-\varepsilon) M S_{21, t-2}
$$

Where $\varepsilon$ is the coefficient representing the relative importance of the market share ratios between retailers 2 and 1 of the previous period and $(1-\varepsilon)$ represents the influence of the period prior to the preceding period. We can say that most likely $\varepsilon>\frac{1}{2}$ according to the law of diminishing influence of longer market share periods.

Therefore by (1.24) and (1.25) we can rewrite the following two values:

$$
A M S_{21, t-1, t-2}=\varepsilon \cdot \frac{q_{2, t-1}}{q_{1, t-1}}+(1-\varepsilon) \cdot \frac{q_{2, t-2}}{q_{1, t-2}}
$$

and

$$
A M S_{12, t-1, t-2}=\varepsilon \cdot \frac{q_{1, t-1}}{q_{2, t-1}}+(1-\varepsilon) \cdot \frac{q_{1, t-2}}{q_{2, t-2}}
$$

Let's define the profit functions of each retailer. From (1.13) (1.14) (1.22) (1.23) and (1.24) we get (1.28).

Therefore the profit function of retailer $i$ is:

$$
\prod_{i, t}^{R}=\left(P_{i, t}^{R}-P_{i, t}^{M}\right) \cdot q_{i, t}+\left(M S_{i, t}-M S_{i, t-1}\right) \cdot P_{i, t}^{R} \cdot q_{i, t} \quad(\text { See Appendix A) }
$$

Where the profit margin can be broken down into two values. The left term of (1.28) represents the profit earned from the regular profit margin of the retailer, and the right-hand second term represents additional profit from the accumulated market share of the retailer based on the difference between current and previous market shares. The economic reasoning for this effect is based on the fact that customers tend to be loyal to stores and form the habit of buying certain products at certain locations.

From (1.28) and (1.23) we get:

$$
\Pi_{1, t}^{R}=\left[(1+\alpha)\left(A_{1}-q_{1, t}\right)-\left(A_{1}-q_{1, t}\right)\right] \cdot q_{1, t}+\left(\frac{q_{1, t}}{\sum_{i=1}^{2} q_{i, t}}-M S_{1, t-1}\right) \cdot\left[(1+\alpha)\left(A_{1}-q_{1, t}\right) \cdot q_{1, t}\right]
$$

or the profit function of retailers 1 and 2 as follows:

$$
\Pi_{1, t}^{R}=\left[\alpha+\left(\frac{1}{1+A M S_{21, t-1, t-2}}-M S_{1, t-1}\right) \cdot(1+\alpha)\right] \cdot \frac{4\left(1+4 \gamma^{2} \delta+3 \gamma^{4} \delta^{2}\right) A_{1}^{2}-8 \gamma^{4} \delta^{2} A_{1} \cdot A_{2}-4 \gamma^{4} \delta^{2} A_{2}^{2}}{4\left(2+4 \gamma^{2} \delta\right)^{2}}
$$

and since 


$$
\Pi_{2, t}^{R}=\left[(1+\alpha)\left(A_{2}-q_{2, t}\right)-\left(A_{2}-q_{2, t}\right)\right] \cdot q_{2, t}+\left(\frac{q_{2, t}}{\sum_{i=1}^{2} q_{i, t}}-M S_{2, t-1}\right) \cdot\left[(1+\alpha)\left(A_{2}-q_{2, t}\right) \cdot q_{2, t}\right]
$$

or

$$
\Pi_{2, t}^{R}=\left[\alpha+\left(\frac{1}{1+A M S_{2, t-1, t-2}}-M S_{2, t-1}\right) \cdot(1+\alpha)\right] \cdot \frac{4\left(1+4 \gamma^{2} \delta+3 \gamma^{4} \delta^{2}\right) A_{2}^{2}-8 \gamma^{4} \delta^{2} A_{1} \cdot A_{2}-4 \gamma^{4} \delta^{2} A_{1}^{2}}{4\left(2+4 \gamma^{2} \delta\right)^{2}}
$$

The last groups of agents who receive some gain from the cheese sales are the consumers whose benefits are measured by their consumer surplus at period $t, C S_{t}$

$$
C S_{t}=\frac{\left[(1+\alpha) A_{1}-P_{i, t}^{R}\right] \cdot q_{1, t}}{2}+\frac{\left[(1+\alpha) A_{2}-P_{2, t}^{R}\right] \cdot q_{2, t}}{2}
$$

The value of $C S_{t}$ can be rewritten as:

$$
C S_{t}=(1+\alpha)\left\{\frac{\left[\left(2+2 \gamma^{2} \delta\right) A_{1}-2 \gamma^{2} \delta \cdot A_{2}\right]^{2}}{8\left(2+4 \gamma^{2} \delta\right)^{2}}+\frac{\left[\left(2+2 \gamma^{2} \delta\right) A_{2}-2 \gamma^{2} \delta \cdot A_{1}\right]^{2}}{8\left(2+4 \gamma^{2} \delta\right)^{2}}\right\}
$$

or

$$
C S_{t}=(1+\alpha)\left\{\frac{\left(1+2 \gamma^{2} \delta+2 \gamma^{4} \delta^{2}\right)\left(A_{1}^{2}+A_{2}^{2}\right)-2 \gamma^{2} \delta \cdot\left(2+2 \gamma^{2} \delta\right) \cdot A_{1} A_{2}}{2\left(2+4 \gamma^{2} \delta\right)^{2}}\right\}
$$

The total welfare of the four types of agents: milk producers, cheese producer, the two retailers, and the consumers is:

That can be summed up as:

$$
W=\Pi^{S}+\Pi_{t}^{M}+\Pi_{1, t}^{R}+\Pi_{2, t}^{R}+C S_{t}
$$

$$
\begin{aligned}
W & =\frac{\left(1+3 \gamma^{2} \delta+2 \gamma^{4} \delta^{2}\right)\left(A_{1}^{2}+A_{2}^{2}\right)-2 \gamma^{2} \delta\left(1+2 \gamma^{2} \delta\right) \cdot A_{1} A_{2}}{\left(2+4 \gamma^{2} \delta\right)^{2}}+\frac{\gamma^{2} \delta\left(A_{1}+A_{2}\right)^{2}}{2\left(2+4 \gamma^{2} \delta\right)^{2}}+ \\
& +\left[\alpha+\left(\frac{1}{1+A M S_{1, t-1, t-2}}-M S_{1, t-1}\right) \cdot(1+\alpha)\right] \cdot \frac{4\left(1+4 \gamma^{2} \delta+3 \gamma^{4} \delta^{2}\right) A_{1}^{2}-8 \gamma^{4} \delta^{2} A_{1} \cdot A_{2}-4 \gamma^{4} \delta^{2} A_{2}^{2}}{4\left(2+4 \gamma^{2} \delta\right)^{2}}+ \\
& +\left[\alpha+\left(\frac{1}{1+A M S_{2, t-1, t-2}}-M S_{2, t-1}\right) \cdot(1+\alpha)\right] \cdot \frac{4\left(1+4 \gamma^{2} \delta+3 \gamma^{4} \delta^{2}\right) A_{2}^{2}-8 \gamma^{4} \delta^{2} A_{1} \cdot A_{2}-4 \gamma^{4} \delta^{2} A_{1}^{2}}{4\left(2+4 \gamma^{2} \delta\right)^{2}}+ \\
& +(1+\alpha)\left\{\frac{\left(1+2 \gamma^{2} \delta+2 \gamma^{4} \delta^{2}\right)\left(A_{1}^{2}+A_{2}^{2}\right)-2 \gamma^{2} \delta \cdot\left(2+2 \gamma^{2} \delta\right) \cdot A_{1} A_{2}}{2\left(2+4 \gamma^{2} \delta\right)^{2}}\right\}
\end{aligned}
$$

or 


$$
\begin{aligned}
W & =\frac{\left((3+\alpha)+\gamma^{2} \delta(9+2 \alpha)+\gamma^{4} \delta^{2}(6+2 \alpha)\right)\left(A_{1}^{2}+A_{2}^{2}\right)-\left(4 \gamma^{4} \delta^{2}(3+\alpha)+2 \gamma^{2} \delta(3+2 \alpha)\right) \cdot A_{1} A_{2}}{2\left(2+4 \gamma^{2} \delta\right)^{2}}+ \\
& +\left[\alpha+\left(\frac{1}{1+A M S_{1, t-1, t-2}}-M S_{1, t-1}\right) \cdot(1+\alpha)\right] \cdot \frac{4\left(1+4 \gamma^{2} \delta+3 \gamma^{4} \delta^{2}\right) A_{1}^{2}-8 \gamma^{4} \delta^{2} A_{1} \cdot A_{2}-4 \gamma^{4} \delta^{2} A_{2}^{2}}{4\left(2+4 \gamma^{2} \delta\right)^{2}}+ \\
& +\left[\alpha+\left(\frac{1}{1+A M S_{2, t-1, t-2}}-M S_{2, t-1}\right) \cdot(1+\alpha)\right] \cdot \frac{4\left(1+4 \gamma^{2} \delta+3 \gamma^{4} \delta^{2}\right) A_{2}^{2}-8 \gamma^{4} \delta^{2} A_{1} \cdot A_{2}-4 \gamma^{4} \delta^{2} A_{1}^{2}}{4\left(2+4 \gamma^{2} \delta\right)^{2}}
\end{aligned}
$$

\section{The Price Ceiling Model}

The previous section continues to assume that the retailers are permitted to add to the price the monopoly producer charges an additional charge of $\alpha$, such that the maximum price imposed on each of the retailers $i$, is identical for both of them. Since the marketers are taking an extra fixed portion of profit, $\alpha$, the real meaning of $P_{\max }$ imposed on retailers is very similar to a price ceiling imposed on a monopoly. We can present this differently in the following way. A price ceiling on a monopoly producer automatically imposes a price ceiling of $(1+\alpha) \overline{\mathrm{P}}$ on both retailers. This presumption makes sense since the other sectors of milk producers and consumers are price takers in our model and therefore the imposition of a price ceiling on both parties is irrelevant.

$$
P_{1}^{R}=P_{2}^{R}=P_{\max }=(1+\alpha) P_{M}
$$

Therefore the monopoly producer's price is also capped by the government for both retailers as:

$$
\begin{gathered}
P_{1, t}^{R}=A_{1}-q_{1, t}=\frac{P \text { max }}{1+\alpha} \\
P_{2, t}^{R}=A_{2}-q_{2, t}=\frac{P \max }{1+\alpha}
\end{gathered}
$$

and the quantities sold to the retailers are:

$$
\bar{q}_{1, t}=A_{1}-\frac{P \max }{1+\alpha}
$$

and

$$
\bar{q}_{2, t}=A_{2}-\frac{P \max }{1+\alpha}
$$

Based on the above equations we can calculate the revenues and profit of the milk producers as follows:

$$
P(s)=\delta \cdot S
$$

$$
S=S_{1}+S_{2}+\cdots S_{i}
$$

The quantity of milk sold by milk producers is:

$Q=\gamma^{-1} S$

Since $Q=\sum_{i=1}^{2} q_{i} \gamma$, then 


$$
S=\sum_{i=1}^{2} q_{i} \gamma=\sum_{i=1}^{2}\left(A_{i}-\frac{P_{\max }}{1+\alpha}\right) \gamma=\left(A_{1}-\frac{P_{\max }}{1+\alpha}+A_{2}-\frac{P_{\max }}{1+\alpha}\right) \gamma
$$

and the profit of the milk producers is:

$$
\Pi^{S}=\frac{\delta \gamma^{2}}{2}\left(A_{1}+A_{2}-\frac{2 P_{\max }}{1+\alpha}\right)^{2}
$$

Since the milk producers' revenues are the monopoly's cost, the monopoly's profit is:

$$
\Pi_{t}^{M}=\sum_{i=1}^{2} \frac{P \max }{1+\alpha} \cdot \bar{q}_{i, t}-P^{S}(S)_{t} \cdot \sum_{j=1}^{n} \bar{S}_{j, t}
$$

From (2.3), (2.4), (2.5) and (2.7) we can rewrite the monopoly's profit in the precise terms of the parameters:

$$
\Pi^{M}{ }_{t}=\frac{P_{\max }}{1+\alpha}\left(A_{1}-\frac{P_{\max }}{1+\alpha}\right)+\frac{P_{\max }}{1+\alpha}\left(A_{2}-\frac{P_{\max }}{1+\alpha}\right)-\gamma^{2} \delta\left(A_{1}-\frac{P_{\max }}{1+\alpha}+A_{2}-\frac{P_{\max }}{1+\alpha}\right)^{2}
$$

or

$$
\Pi_{t}^{M}=\frac{P_{\max }}{1+\alpha}\left(A_{1}+A_{2}-\frac{2 P_{\max }}{1+\alpha}\right)-\gamma^{2} \delta\left(A_{1}+A_{2}-\frac{2 P_{\max }}{1+\alpha}\right)^{2}
$$

The next stage investigates the retailers' profits, that is:

$$
\prod_{i, t}^{R}=\left(P_{i, t}^{R}-P_{i, t}^{M}\right) \cdot q_{i, t}+\left(M S_{i, t}-M S_{i, t-1}\right) \cdot P_{i, t}^{R} \cdot q_{i, t}
$$

Therefore, based on (2.2) the profit of retailer 1 is:

$$
\Pi_{1, t}^{R}=\left(P_{\max }-\frac{p_{\max }}{1+\alpha}\right)\left(A_{1}-\frac{P_{\max }}{1+\alpha}\right)+\left(M S_{1, t}-M S_{1, t-1}\right) \cdot P_{\max } \cdot\left(A_{1}-\frac{P_{\max }}{1+\alpha}\right)
$$

or,

$$
\prod_{1, t}^{R}=\left(A_{1}-\frac{P_{\max }}{1+\alpha}\right)\left[\frac{\alpha}{1+\alpha}+M S_{1, t}-M S_{1, t-1}\right] P_{\max }
$$

Thus the profit of retailer 2 is:

$$
\Pi_{2, t}^{R}=\left(P_{R_{i, t}}-P_{M_{i, t}}\right) \cdot \bar{q}_{2, t}+\left(M S_{2, t}-M S_{2, t-1}\right) \cdot P_{R_{i, t}} \cdot \bar{q}_{2, t}
$$

Again, based on (2.2b) the profit of retailer 2 is:

$$
\Pi_{2, t}^{R}=\left(P_{\max }-\frac{p_{\text {max }}}{1+\alpha}\right)\left(A_{2}-\frac{P_{\max }}{1+\alpha}\right)+\left(M S_{2, t}-M S_{2, t-1}\right) \cdot P_{\max } \cdot\left(A_{2}-\frac{P_{\max }}{1+\alpha}\right)
$$

or

$$
\Pi_{1, t}^{R}=\left(A_{1}-\frac{P_{\max }}{1+\alpha}\right)\left[\frac{\alpha}{1+\alpha}+M S_{2, t}-M S_{2, t-1}\right] P_{\max }
$$

The total profit of the retailers' sector is:

$$
\Pi^{R}=\left(A_{1}-\frac{P_{\max }}{1+\alpha}\right)\left[\frac{\alpha}{1+\alpha}+M S_{1, t}-M S_{1, t-1}\right] P_{\max }+\left(A_{2}-\frac{P_{\max }}{1+\alpha}\right)\left[\frac{\alpha}{1+\alpha}+M S_{2, t}-M S_{2, t-1}\right] P_{\max }
$$

or

$$
\Pi^{R}=\left(A_{1}-\frac{P_{\max }}{1+\alpha}\right)\left[\frac{\alpha}{1+\alpha}+M S_{1, t}-M S_{1, t-1}\right] P_{\max }+\left(A_{2}-\frac{P_{\max }}{1+\alpha}\right)\left[\frac{\alpha}{1+\alpha}+\left(1-M S_{1, t}\right)-\left(1-M S_{1, t-1}\right)\right] P_{\max }
$$


or

$$
\Pi^{R}=\frac{\alpha}{1+\alpha}\left(A_{1}+A_{2}\right) P_{\max }+\left(M S_{1, t}-M S_{1, t-1}\right)\left(A_{1}-A_{2}\right) P_{\max }-\frac{2 \alpha \cdot P_{\max }^{2}}{(1+\alpha)^{2}}
$$

The consumer surplus under the price ceiling is:

$$
C S_{t}=\sum_{i=1}^{2} \frac{\left[(1+\alpha) A_{i}-P_{\max }\right]}{2} q_{i, t}
$$

or

$$
C S_{t}=\frac{\left[(1+\alpha) A_{1}-P_{\max }\right]}{2}\left(A_{1}-\frac{p_{\max }}{1+\alpha}\right)+\frac{\left[(1+\alpha) A_{2}-P_{\max }\right]}{2}\left(A_{2}-\frac{p_{\max }}{1+\alpha}\right)
$$

or

$$
\frac{(1+\alpha)\left(A_{1}^{2}+A_{2}^{2}\right)}{2}-P_{\max }\left(A_{1}+A_{2}\right)+\frac{p_{\max }^{2}}{1+\alpha}
$$

The total welfare of the "entire economy" under the price ceiling regime is:

$$
\begin{aligned}
W & =\frac{P_{\max }}{1+\alpha}\left(A_{1}+A_{2}-\frac{2 P_{\max }}{1+\alpha}\right)-\gamma^{2} \delta\left(A_{1}+A_{2}-\frac{2 P_{\max }}{1+\alpha}\right)^{2}+\frac{\delta \gamma^{2}}{2}\left(A_{1}+A_{2}-\frac{2 P_{\max }}{1+\alpha}\right)^{2}+ \\
& +\frac{\alpha}{1+\alpha}\left(A_{1}+A_{2}\right) P_{\max }+\left(M S_{1, t}-M S_{1, t-1}\right)\left(A_{1}-A_{2}\right) P_{\max }-\frac{2 \alpha P_{\max }^{2}}{(1+\alpha)^{2}}+ \\
& +\frac{(1+\alpha)\left(A_{1}^{2}+A_{2}^{2}\right)}{2}-P_{\text {max }}\left(A_{1}+A_{2}\right)+\frac{p_{\max }^{2}}{1+\alpha}
\end{aligned}
$$

or

$$
\begin{aligned}
W & =\frac{P_{\max }}{1+\alpha}\left(A_{1}+A_{2}-\frac{2 P_{\max }}{1+\alpha}\right)-\frac{\delta \gamma^{2}}{2}\left(A_{1}+A_{2}-\frac{2 P_{\max }}{1+\alpha}\right)^{2}+ \\
& +\frac{\alpha}{1+\alpha}\left(A_{1}+A_{2}\right) P_{\max }+\left(M S_{1, t}-M S_{1, t-1}\right)\left(A_{1}-A_{2}\right) P_{\max }-\frac{2 \alpha \cdot P_{\max }^{2}}{(1+\alpha)^{2}}+ \\
& +\frac{(1+\alpha)\left(A_{1}^{2}+A_{2}^{2}\right)}{2}-P_{\text {max }}\left(A_{1}+A_{2}\right)+\frac{p_{\max }^{2}}{1+\alpha}
\end{aligned}
$$

Since we assume that price ceiling policy is used by a policymaker just with respect to total welfare (the size of the total pie) irrespective of the size of the various shares or slices of the pie, the objective function of the policymaker is to take the derivative of $W$ with respect to $P_{\max }$ as follows:

$$
\begin{aligned}
\frac{d W}{d P_{\max }} & =\left(A_{1}+A_{2}-\frac{2 P_{\max }}{1+\alpha}\right) \frac{1}{1+\alpha}-\frac{2 P_{\max }}{(1+\alpha)^{2}}+\frac{2 \gamma^{2} \delta}{1+\alpha}\left(A_{1}+A_{2}-\frac{2 P_{\max }}{1+\alpha}\right)+ \\
& +\frac{\alpha}{1+\alpha}\left(A_{1}+A_{2}\right)+\left(M S_{1, t}-M S_{1, t-1}\right)\left(A_{1}-A_{2}\right)-\frac{4 \alpha P_{\max }}{(1+\alpha)^{2}}- \\
& -\left(A_{1}+A_{2}\right)+\frac{2 P_{\max }}{1+\alpha}=0
\end{aligned}
$$

or

$$
\frac{d W}{d P_{\max }}=\frac{2 \gamma^{2} \delta}{1+\alpha}\left(A_{1}+A_{2}\right)+\left(M S_{1, t}-M S_{1, t-1}\right)\left(A_{1}-A_{2}\right)-P_{\max } \frac{2\left(1+\alpha+2 \gamma^{2} \delta\right)}{(1+\alpha)^{2}}=0
$$


That yields optimal $P_{\max }$ as:

$$
P_{\max }=\frac{(1+\alpha) 2 \gamma^{2} \delta}{2\left(1+\alpha+2 \gamma^{2} \delta\right)}\left(A_{1}+A_{2}\right)+\frac{(1+\alpha)^{2}}{2\left(1+\alpha+2 \gamma^{2} \delta\right)}\left(M S_{1, t}-M S_{1, t-1}\right)\left(A_{1}-A_{2}\right)
$$

We define:

$$
X=\left(M S_{1, t}-M S_{1, t-1}\right) ; \quad Y=\frac{(1+\alpha)^{2}}{2\left(1+\alpha+2 \gamma^{2} \delta\right)} \quad ; \quad Z=\frac{(1+\alpha) 2 \gamma^{2} \delta}{2\left(1+\alpha+2 \gamma^{2} \delta\right)}
$$

Then,

$$
P_{\max }=Z\left(A_{1}+A_{2}\right)+Y X\left(A_{1}-A_{2}\right)
$$

or

$$
\bar{q}_{1, t}=A_{1}-\frac{P \max }{1+\alpha}=A_{1}-\frac{Z\left(A_{1}+A_{2}\right)+Y X\left(A_{1}-A_{2}\right)}{1+\alpha}=\frac{A_{1}(1+\alpha)-Z\left(A_{1}+A_{2}\right)-Y X\left(A_{1}-A_{2}\right)}{1+\alpha}
$$

and

$$
\bar{q}_{2, t}=A_{2}-\frac{P \max }{1+\alpha}=A_{2}-\frac{Z\left(A_{1}+A_{2}\right)+Y X\left(A_{1}-A_{2}\right)}{1+\alpha}=\frac{A_{2}(1+\alpha)-Z\left(A_{1}+A_{2}\right)-Y X\left(A_{1}-A_{2}\right)}{1+\alpha}
$$

While the monopoly's profit from the total sales to both retailers is:

$$
\Pi_{t}^{M}=\frac{P_{\max }}{1+\alpha}\left(A_{1}+A_{2}-\frac{2 P_{\max }}{1+\alpha}\right)-\gamma^{2} \delta\left(A_{1}+A_{2}-\frac{2 P_{\max }}{1+\alpha}\right)^{2}
$$

or

$$
\Pi_{t}^{M}=\frac{Z\left(A_{1}+A_{2}\right)+Y X\left(A_{1}-A_{2}\right)}{1+\alpha}\left(A_{1}+A_{2}-\frac{2\left(Z\left(A_{1}+A_{2}\right)+Y X\left(A_{1}-A_{2}\right)\right)}{1+\alpha}\right)-\gamma^{2} \delta\left(A_{1}+A_{2}-\frac{2\left(Z\left(A_{1}+A_{2}\right)+Y X\left(A_{1}-A_{2}\right)\right)}{1+\alpha}\right)^{2}
$$

Thus, their total profits are:

$$
\Pi^{S}=\frac{\delta \gamma^{2}}{2}\left(A_{1}+A_{2}-\frac{2 P_{\max }}{1+\alpha}\right)^{2}
$$

or

$$
\Pi^{S}=\frac{\delta \gamma^{2}}{2}\left[A_{1}+A_{2}-\frac{2\left(Z\left(A_{1}+A_{2}\right)+Y X\left(A_{1}-A_{2}\right)\right)}{1+\alpha}\right]
$$

On the other hand the retailers' profits are summarized below, such that the profit of retailer 1 is:

$$
\prod_{i, t}^{R}=\left(A_{1}-\frac{P_{\max }}{1+\alpha}\right) \cdot\left[\left(\frac{\alpha}{1+\alpha}\right)+M S_{1, t}-M S_{1, t-1}\right] \cdot P_{\max }
$$

or

$$
\prod_{i, t}^{R}=\left[\frac{A_{1}(1+\alpha)-Z\left(A_{1}+A_{2}\right)-Y X\left(A_{1}-A_{2}\right)}{1+\alpha}\right] \cdot\left[\left(\frac{\alpha}{1+\alpha}\right)+M S_{, t}-M S_{, t-1}\right] \cdot\left[Z\left(A_{1}+A_{2}\right)-Y X\left(A_{1}-A_{2}\right)\right]
$$

and for retailer 2 the profit is:

$$
\prod_{2, t}^{R}=\left(A_{1}-\frac{P_{\max }}{1+\alpha}\right) \cdot\left[\left(\frac{\alpha}{1+\alpha}\right)+M S_{2, t}-M S_{2, t-1}\right] \cdot P_{\max }
$$

or 


$$
\Pi_{2, t}^{R}=\left[\frac{A_{1}(1+\alpha)-Z\left(A_{1}+A_{2}\right)-Y X\left(A_{1}-A_{2}\right)}{1+\alpha}\right] \cdot\left[\left(\frac{\alpha}{1+\alpha}\right)+M S_{2, t}-M S_{2, t-1}\right] \cdot\left[Z\left(A_{1}+A_{2}\right)-Y X\left(A_{1}-A_{2}\right)\right]
$$

The fourth sector that gains from the price ceiling policy is the consumer sector for which its consumer surplus added up to:

$$
\begin{gathered}
C S_{t}=\frac{(1+\alpha)\left(A_{1}^{2}+A_{2}^{2}\right)}{2}-P_{\max }\left(A_{1}+A_{2}\right)-\frac{p_{\max }{ }^{2}}{1+\alpha} \\
C S_{t}=\frac{(1+\alpha)\left(A_{1}^{2}+A_{2}^{2}\right)}{2}-\left[Z\left(A_{1}+A_{2}\right)+Y X\left(A_{1}-A_{2}\right)\right]\left(A_{1}+A_{2}\right)-\frac{Z\left(A_{1}+A_{2}\right)+Y X\left(A_{1}-A_{2}\right)^{2}}{1+\alpha}
\end{gathered}
$$

or

$$
C S_{t}=\frac{(1+\alpha)\left(A_{1}^{2}+A_{2}^{2}\right)}{2}-\left[Z\left(A_{1}+A_{2}\right)^{2}+Y X\left(A_{1}^{2}-A_{2}^{2}\right)\right]-\frac{Z\left(A_{1}+A_{2}\right)+Y X\left(A_{1}-A_{2}\right)^{2}}{1+\alpha}
$$

\section{A Comparison between the Free Market Scenario and the Price Ceiling Scenario}

At this stage of the analysis we want to make comparisons between the total welfare gained in the free market system as compared with the case in which a policymaker intervenes for the sake of welfare maximization. It is clear that the total welfare should increase as a result of the price ceiling. However, the specific shares among the economic agents of the larger pie that is generated by the intervention are unclear. In the simple market structure, when only two parties face each other as rivals, i.e., the consumers and the monopoly producer, the picture is very clear. In that case total welfare increases since with a price ceiling the gain to consumers in terms of consumer surplus is greater than the profit reduction of the monopoly. However, in the present analysis the supply chain consists of three representatives (links) on the supply side.

Do all three of the suppliers that are the milk producers, monopoly cheese producer and the two retailers all lose and if so, are their losses proportional? If the losses are not proportional, who loses less and who loses more? Is it possible that some may even gain, especially if their power under the free market regime was negligible, such as that of the milk producers? These questions are worthy of investigation since a-priori we may know that overall the suppliers are losing, but the question is who may be hurt more. Are we penalizing those who are really responsible for the welfare losses under a competitive free market structure or do those actually responsible for the welfare loss have the economic power to pass the burden of the price ceiling on to other "innocent" and less powerful agents? If indeed the policymaker realizes that this may actually occur, then the price ceiling policy should be carefully reexamined. These are the kind of considerations introduced below using the following specific five values:

a) the consumer surplus of cheese customers, b) the profits of milk producers, c) the profits of cheese producers, d) the profits of retailers, e) the total welfare under the two scenarios of free market and price control based on different parameter values.

Based on several simulations in the free market and the controlled scenarios we find that under a non-regulated regime (free market) the supply chain "captures" about seventy percent of the total welfare and most of it is shared by the monopoly producer and the duopoly retailers with negligible profits for the milk producers. $30 \%$ of the total welfare is gained by the consumers. Consumers and milk producers operate in a competitive environment and therefore their shares are not affected by a parameter that represents the profit margin of the retailers, such that a larger $\alpha$ indicates more "monopoly power". However, as $\alpha$ increases the additional gains of the retailers are taken from the monopoly cheese producer. Its relative share is shrinking and has almost no effect on the other agents. All of the preceding discussion has only dealt with the percentage with respect to the total welfare. Several simulations that are included in Tables 1 to 4 below are followed by the four figures. 
Table 1. The relationship between coefficient $\alpha$ and aggregate welfare values

\begin{tabular}{cccccc}
\hline $\boldsymbol{\alpha}$ & Producer & Monopoly & Retailers & $\begin{array}{c}\text { Consumer } \\
\text { Surplus }\end{array}$ & Welfare \\
\hline 0 & 10 & $8,105.52$ & 125.00 & $4,043.04$ & $12,283.28$ \\
0.1 & 10 & $8,105.52$ & $1,018.75$ & $4,447.35$ & $13,581.33$ \\
0.2 & 10 & $8,105.52$ & $1,924.99$ & $4,851.65$ & $14,891.87$ \\
0.3 & 10 & $8,105.52$ & $2,843.74$ & $5,255.95$ & $16,214.92$ \\
0.4 & 10 & $8,105.52$ & $3,774.98$ & $5,660.26$ & $17,550.47$ \\
0.5 & 10 & $8,105.52$ & $4,718.73$ & $6,064.56$ & $18,898.52$ \\
0.6 & 10 & $8,105.52$ & $5,674.97$ & $6,468.87$ & $20,259.07$ \\
0.7 & 10 & $8,105.52$ & $6,643.72$ & $6,873.17$ & $21,632.12$ \\
0.8 & 10 & $8,105.52$ & $7,624.96$ & $7,277.48$ & $23,017.67$ \\
0.9 & 10 & $8,105.52$ & $8,618.71$ & $7,681.78$ & $24,415.72$ \\
1 & 10 & $8,105.52$ & $9,624.95$ & $8,086.08$ & $25,826.27$ \\
\hline
\end{tabular}

Table 2. The relationship between the coefficient $\alpha$ and the price ratios of $\mathrm{P}_{\max } / \mathrm{P}^{*}$

\begin{tabular}{cc}
\hline $\boldsymbol{\alpha}$ & $\mathbf{P}_{\max } / \mathbf{p}^{*}$ \\
\hline 0 & $0.58 \%$ \\
0.1 & $0.82 \%$ \\
0.2 & $1.06 \%$ \\
0.3 & $1.32 \%$ \\
0.4 & $1.58 \%$ \\
0.5 & $1.85 \%$ \\
0.6 & $2.13 \%$ \\
0.7 & $2.41 \%$ \\
0.8 & $2.69 \%$ \\
0.9 & $2.98 \%$ \\
1 & $3.27 \%$ \\
\hline
\end{tabular}

Table 3. The relationship between coefficient $\alpha$ and the suppliers' profits

\begin{tabular}{cccc}
\hline $\boldsymbol{\alpha}$ & Producer & Monopoly & Retailers \\
\hline 0 & $54.64 \%$ & $44.12 \%$ & $1.23 \%$ \\
0.1 & $29.52 \%$ & $57.30 \%$ & $13.18 \%$ \\
0.2 & $19.01 \%$ & $59.59 \%$ & $21.41 \%$ \\
0.3 & $13.40 \%$ & $58.70 \%$ & $27.89 \%$ \\
0.4 & $10.00 \%$ & $56.71 \%$ & $33.29 \%$ \\
0.5 & $7.77 \%$ & $54.33 \%$ & $37.90 \%$ \\
0.6 & $6.21 \%$ & $51.88 \%$ & $41.91 \%$ \\
0.7 & $5.08 \%$ & $49.48 \%$ & $45.45 \%$ \\
0.8 & $4.23 \%$ & $47.19 \%$ & $48.59 \%$ \\
0.9 & $3.57 \%$ & $45.03 \%$ & $51.40 \%$ \\
1 & $3.06 \%$ & $43.01 \%$ & $53.93 \%$ \\
\hline
\end{tabular}


Table 4. The relationship between coefficient $\alpha$ and the gaps of the aggregate welfare values

\begin{tabular}{cccccc}
\hline $\boldsymbol{\alpha}$ & $\boldsymbol{\Delta}$ Producer & $\boldsymbol{\Delta \text { Monopoly }}$ & $\Delta$ Retailer & $\begin{array}{c}\Delta \text { Consumer } \\
\text { Surplus }\end{array}$ & $\Delta$ Welfare \\
\hline 0 & 29 & $-8,074$ & -124 & 12,097 & 3,928 \\
0.1 & 29 & $-8,030$ & $-1,001$ & 13,259 & 4,256 \\
0.2 & 29 & $-7,985$ & $-1,882$ & 14,408 & 4,571 \\
0.3 & 29 & $-7,937$ & $-2,764$ & 15,546 & 4,874 \\
0.4 & 29 & $-7,888$ & $-3,647$ & 16,672 & 5,165 \\
0.5 & 28 & $-7,838$ & $-4,532$ & 17,786 & 5,444 \\
0.6 & 28 & $-7,787$ & $-5,418$ & 18,888 & 5,711 \\
0.7 & 28 & $-7,736$ & $-6,304$ & 19,978 & 5,966 \\
0.8 & 28 & $-7,683$ & $-7,190$ & 21,055 & 6,209 \\
0.9 & 28 & $-7,631$ & $-8,077$ & 22,119 & 6,440 \\
1 & 28 & $-7,577$ & $-8,963$ & 23,171 & 6,659 \\
\hline
\end{tabular}

Figure 1 demonstrates the total value of welfare and its distribution among consumers and the supply chain agents. Here the ability of retailers to increase their gains by allowing the higher profit margin $\alpha$ leads to an increase in efficiency as measured by a larger total welfare. Most of the extra financial gains are obtained by the retailers as can be expected, but the monopoly gains almost nothing despite producing more cheese. The milk producers also do not gain and the only other sector that gains from a larger $\alpha$ are the customers who gain 30\% of the total welfare. The figure illustrates that the elasticity of consumer surplus with respect to the welfare is unitary, while the elasticity of retailers with respect to welfare is larger than one.

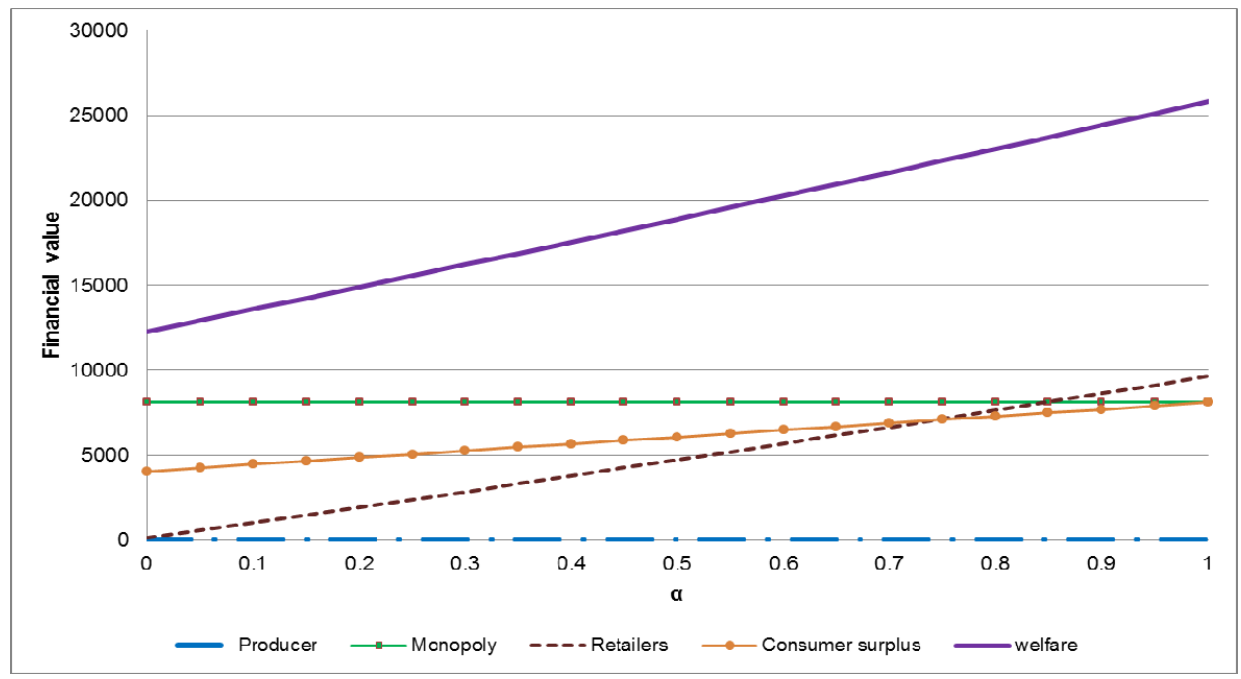

Figure 1. The relationship between coefficient $\alpha$ and aggregate welfare values

The main power of retailers that is created by allowing a larger $\alpha$ is imposed on the monopoly producer and not on the consumers or the competing milk producers. In the case of a price ceiling we can identify another unexpected phenomenon. It can be reasonable to assume that the higher profit margin that exists in the retailer's market requires a higher $P_{\max }$, i.e., a smaller gap between the price that is set by free market and that set by the regulator. However, the model shows that the $P_{\max }$ imposed for any given profit margin, $\alpha$, increases more 
rapidly than the change in $\alpha$. In a market with no retailers, $P_{\max }$ is positive but small. However, a larger profit margin leads to a price ceiling that is higher and increases relatively faster (by larger percentages) towards the free market price (see Figure 2).

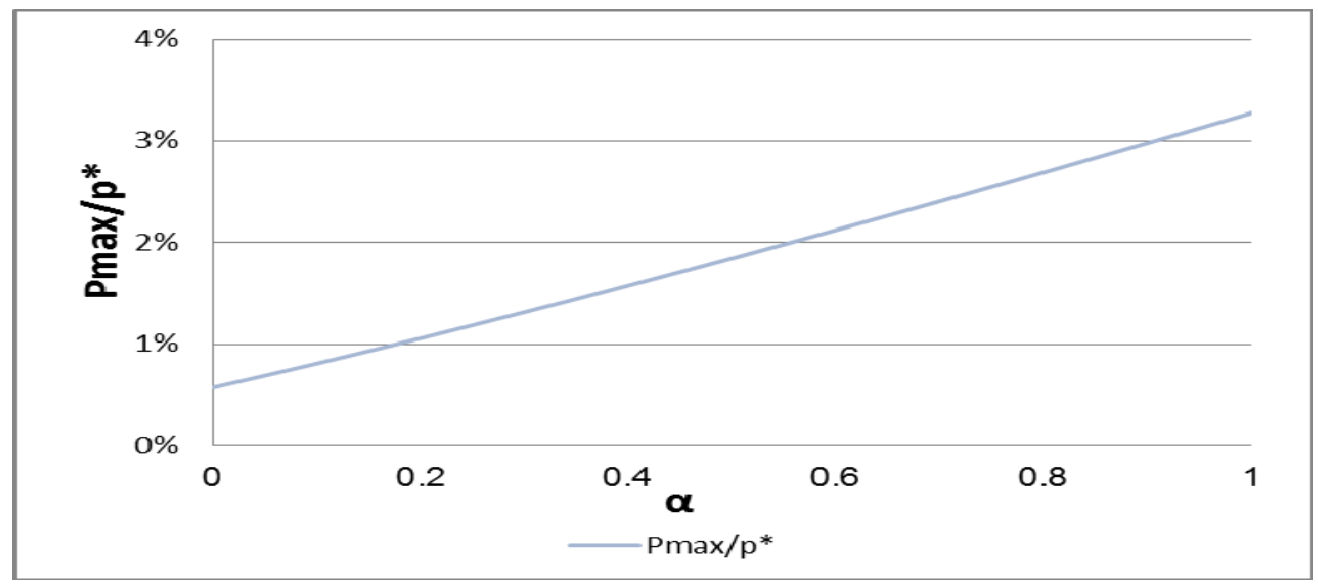

Figure 2. The relationship between the coefficient $\alpha$ and the price ratios of $\mathrm{P}_{\max } / \mathrm{P}^{*}$

In spite of the fact that a larger profit margin indicates larger monopoly power of the retailers, the price set by the free market will be affected positively by this power. However, the appropriate treatment applied by policymakers for the sake of welfare maximization is enforcement of lenient behavior, without very strict price ceiling enforcement, thereby allowing a larger portion of the welfare to be distributed to the supply agents. This is shown very clearly in Figure 3. With changes in $\alpha$, the milk producer's profit as a percentage of the total profit of the whole supply chain is significantly very high. The retailers, with a low profit margin, $\alpha$, gain very little as $\alpha$ increases towards a value of $20 \%$ above the profit of the monopoly cheese producer. The milk producers face a significant decrease in their profit level while the monopoly and the retailers gain. For a larger value of $\alpha$ the monopoly producer starts losing its share in a manner similar to that of the milk producers, and all the extra increases in the relative share is gained by the retailers. A price ceiling policy that is imposed on the supply chain results not only in a profit reduction but also in a redistribution effect on the various agents along the chain. However, each agent along the chain may be affected differently.

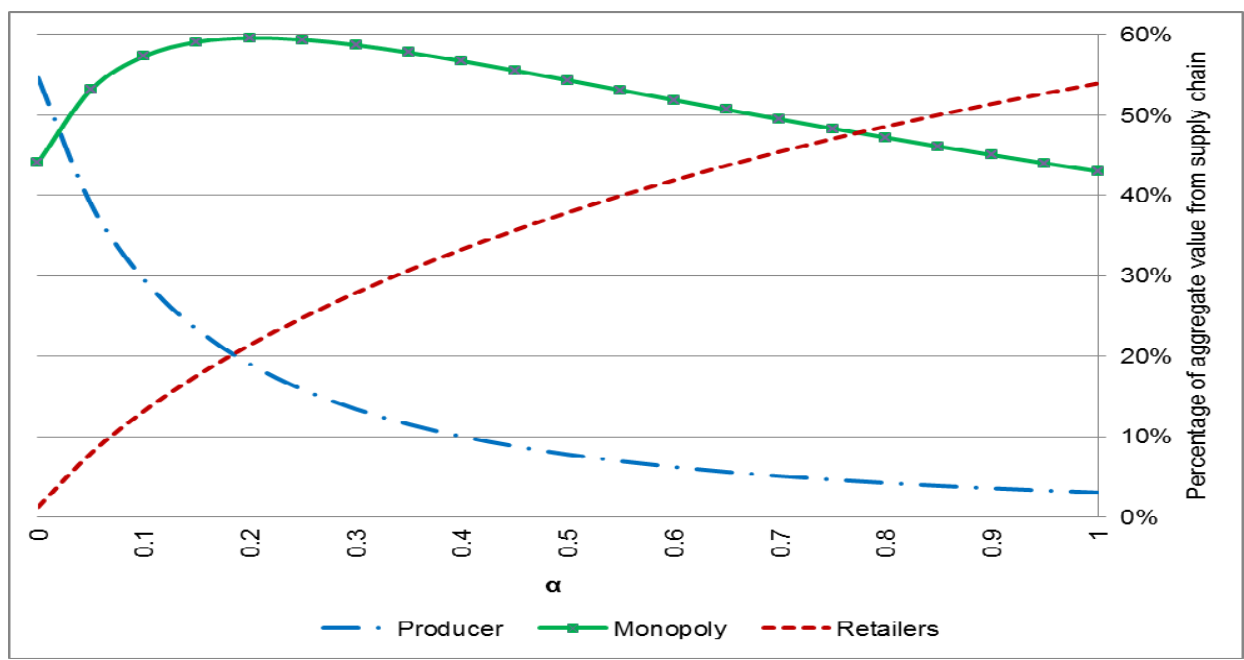

Figure 3. The relationship between coefficient $\alpha$ and the suppliers' profits 
As Figure 4 demonstrates, in financial terms the price ceiling policy leads to a significant increase in the consumer welfare while the total welfare increases with $\alpha$ very slowly. This is a result of profit reduction from the price ceiling imposed on the retailers which becomes more significant as $\alpha$.

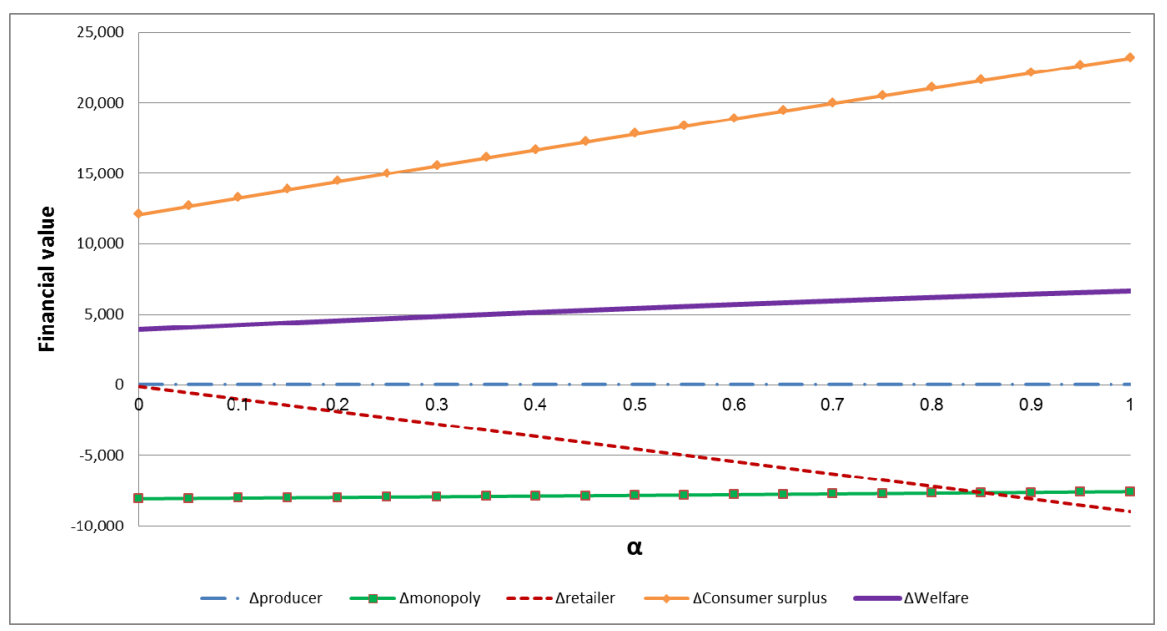

Figure 4. The relationship between coefficient $\alpha$ and the gaps of the aggregate welfare values

The monopoly cheese producer exploits the price ceiling on retailers and even gains from the ceiling on its competitors such that with a larger $\alpha$ the monopoly has more profit than in the free market scenario.

The milk producers that do not have much profit in any case are not influenced when the price ceiling is imposed on the retailers.

As in nature, the strong, stubborn and powerful tree breaks in a storm while the flexible and weak plants survive. The same results are obtained if we take a picture in an appropriate resolution when the supply chain includes strong and weak economic agents facing a regulation technique used by the policymaker. Some may gain, some may lose and some may remain unaffected.

\section{Conclusion}

Since the price ceiling in the cheese industry is applied at the final stage of the supply chain, i.e., the price mark-up is set between retailers and consumers, it may affect in different ways the share of the total welfare, as well as the size of the welfare itself for other suppliers along the supply chain. These redistributional effects along the supply chain links are of major importance and must be taken into account. They may even affect the decision (under various scenarios) determining at which link along the supply chain price controls should be imposed.

In general, regulation and control of non-competitive markets in a supply chain environment is a very difficult task since the source that maintains and accelerates monopoly induced price increases is unclear. In such a case it is very hard to discover the agent along the supply chain that is responsible for the price increase and that generates the pure economic profits that are "too high". As a result, it is also unclear what kind of intervention is more effective. As an example, the policy of opening a domestic monopoly market to competitive imports is most likely not the best solution. It may affect producers with low profit margins along the supply chain and not retailers who may gain a large profit margin due to their high degree of monopoly power.

Recently, prices of basic items of food such as dairy products, vegetable and fruits have increased very significantly in several countries. The policymaker that might also have considered subsidies to farmers tried instead to impose a policy of opening the domestic markets to the lower prices of imported products. The farmers claimed that this policy might harm domestic agriculture but would not necessarily reduce prices to customers, since the retailers impose high monopolistic profit margins that may even increase if the retailers buy the imported inexpensive items and resell them at high prices. 
In the current literature as referenced in the Introduction, we find a similar phenomenon in the pharmacy industry and the gasoline market where a similar supply chain exists. Therefore effective regulation policies should be considered, as in the former example of agricultural products.

\section{References}

Ball, D. (2011). The regulation of mark-ups in the pharmaceutical supply chain, WHO/HAI project on medicine prices and availability. Review Series on Pharmaceutical Pricing Policies and Interventions, Working paper 3.

Bandyopadhyay, S., \& Paul, A. (2010). Equilibrium returns policies in the presence of supplier competition. Marketing Science, 29(5), 846-857. https://doi.org/10.1287/mksc.1100.0563

Biglaiser, G., \& Riordan, M. (2000). Dynamics of price regulation. RAND Journal of Economics, 31(4), 744-767. https://doi.org/10.2307/2696357

Cachon, G. P., \& Lariviere, M. A. (2005). Supply chain coordination with revenue-sharing contract: Strengths and limitation. Management Science, 51, 31-44. https://doi.org/10.1287/mnsc.1040.0215

Doyon, M. (2011). Canada's dairy supply management: Comprehensive review and outlook for the future. Série Discussion CIRANO DT-01, Montréal.

Krishnan, H., \& Winter, R. (2007). Vertical control of price and inventory. American Economic Review, 97, 1840-1857. https://doi.org/10.1257/aer.97.5.1840

Krishnan, H., \& Winter, R. (2010). Inventory dynamics and supply chain coordination. Management Science, 56(1), 141-147. https://doi.org/10.1287/mnsc.1090.1100

Lee, H. L., \& Billington, C. (1993). Material management in decentralized supply chains. Operations Research, 41(5), 835-847. https://doi.org/10.1287/opre.41.5.835

Lokendra, D. R. K., Amit, P. M., Sanjeev, S., \& Kripa, S. (2013). Individually rational buyback contracts with inventory level dependent demand. International Journal of Production Economics, 381-387.

Morton, F. M. S. (2001). The problem of price controls: History shows that these policies lead to shortages and stagnation; so why do we want to control prescription drug prices? Regulation, 24(1), 50-54.

Pasternack, B. (1985). Optimal pricing and return policies for perishable commodities. Marketing Science, 4(2), 166-176. https://doi.org/10.1287/mksc.4.2.166

Rudakova, T. A., Sannikova, I. N., \& Shavandina, O. A. (2015). Analysis of the competitive environment in motor fuel regional market. Review of European Studies, 4(3), 276-285. https://doi.org/10.5539/res.v7n3p276

Savaskan, C., Bhattacharya, S., \& Van Wassenhove, L. M. (2004). Closed-loop supply chain models with product remanufacturing. Management Science, 50(2), 239-252. https://doi.org/10.1287/mnsc. 1030.0186

Shen, Y., \& Willems, S. P. (2012). Coordinating a channel with asymmetric cost information and the manufacturer's optimality. International Journal of Production Economics, 135(1), 125-135. https://doi.org/10.1016/j.ijpe.2010.11.012

Song, Y., Ray, S., \& Li, S. (2008). Structural properties of buyback contracts for price-setting newsvendors. Manufacturing and Service Operations Management, 10(1), 1-18. https://doi.org/10.1287/msom.1060.0140

Spence, M. A. (1975). Monopoly, quality and regulation. The Bell Journal of Economics, 6(2), 417-429. https://doi.org/10.2307/3003237

Spengler, J. J. (1950). Vertical integration and antitrust policy. Journal of Political Economy, 58(4), 347-352. https://doi.org/10.1086/256964

\section{Note}

Note 1 . We thank the very helpful anonymous referee for recommending the use and citation of the Lee and Billington (1993) paper. 


\section{Appendix A}

$A .1 \Pi_{1, t}^{R}=\alpha\left(A_{1}-q_{1, t-1}\right) \cdot q_{1, t}+\left(\frac{q_{1, t}}{\sum_{i=1}^{2} q_{i, t}}-M S_{1, t-1}\right) \cdot(1+\alpha)\left(A_{1}-q_{1, t-1}\right) \cdot q_{1, t}$

$A .2 \frac{q_{1, t}}{\sum_{i=1}^{2} q_{i, t}}=\frac{\frac{A_{1}-q_{1, t-1}}{2 \gamma^{2} \delta \cdot\left(1+A M S_{21, t-1, t-2}\right)}}{\frac{A_{1}-q_{1, t-1}}{2 \gamma^{2} \delta \cdot\left(1+A M S_{21, t-1, t-2}\right)} \cdot\left(1+A M S_{21, t-1, t-2}\right)}$

$A .3 \frac{q_{1, t}}{\sum_{i=1}^{2} q_{i, t}}=\frac{1}{1+A M S_{21, t-1, t-2}}$

\section{Copyrights}

Copyright for this article is retained by the author(s), with first publication rights granted to the journal.

This is an open-access article distributed under the terms and conditions of the Creative Commons Attribution license (http://creativecommons.org/licenses/by/4.0/). 